Meta-Cognitive Reasoning is Associated with Distrust in Polls, Independent of Motivated Reasoning

\author{
Jeffrey Lees ${ }^{12 \uparrow *}$, Barry Lam ${ }^{3}$, Sara Purinton ${ }^{4}$, Daniel Wodak ${ }^{4}$
}

${ }^{1}$ Andlinger Center for Energy and the Environment, Princeton University

${ }^{2}$ Media Forensics Hub, Clemson University

${ }^{3}$ Department of Philosophy, UC Riverside

${ }^{4}$ Department of Philosophy, University of Pennsylvania

$\dagger$ First author. Secondary authors are listed alphabetically.

* Authors' Correspondence: Jeffrey Lees (jeffrey.m.lees@gmail.com)

This working paper is currently under peer review

Keywords: Polls, motivated reasoning, meta-cognition, social judgment Open Materials: https://osf.io/cpx37/

Preprint: https://osf.io/53hc7/ 


\begin{abstract}
In light of perceived polling failures during the 2016 and 2020 U.S. Elections, scholars have highlighted motivated reasoning as a source of distrust, where individuals judge polls by whether they conflict with prior attitudes. Yet a separate, domain-general explanation also exists: meta-cognitive reasoning (i.e., thinking about the thoughts, attitudes, and motives of others). On this view, people distrust polls because they worry respondents are not honest or that pollsters are biased, independent of polls' predicted outcomes. To examine this hypothesis we conducted three studies using Prolific online samples of US Americans. Study 1, conducted five days before the 2020 U.S. Election, found that meta-cognitive concerns were uniquely associated with distrust of 56 polls, above motivated reasoning. Study 2 presented participants with foreign election polls and fictional polls, contexts where motivated reasoning could not plausibly arise, and observed the same associations as Study 1. Study 3 exposed participants to accurate and inaccurate polls from the 2020 Election. Inaccuracy caused an increase in distrust and negative meta-cognitive attributions, independent of whether a poll's inaccuracy benefitted the in-party or not. Our results demonstrate that meta-cognitive reasoning about pollsters and the people polled plays an independent role in poll distrust.
\end{abstract}




\section{TRUST IN POLLS}

\section{Introduction}

The United States is awash with polling data about everything from political opinions to consumer choices. Yet despite the increased availability of polling information and the rise of poll aggregators such as www.FiveThirtyEight.com (Jackson, 2018), public skepticism about polling results is high, with a 2018 poll finding that $52 \%$ of Americans do not believe most or almost all polls reported in the media (Sheffield, 2018).

So what constitutes the best explanation for distrust in polls? A superordinate possibility is that widespread public perceptions that polls were wrong in both the 2016 (Mercer et al., 2016) and 2020 (Cohn, 2020) U.S. Presidential Elections may be driving growing distrust in polls, although substantial cynicism toward polls among the American public can be observed as early as the 2000 Presidential Election (Price \& Stroud, 2005). It is true that, on basic inductive grounds, reasonable people should be less trusting of polls when they have been inaccurate in high-profile cases. But polls are also accurate in a wide range of cases, some of which are high profile, such as the 2012 national and 2018 midterm elections. We therefore need a theory as to the psychological processes which influence how people continue to distrust polls in light of both their failures and successes.

One potential psychological process is motivated reasoning, the well-documented phenomenon of individuals rejecting information that conflicts with their prior beliefs and strongly held attitudes (Brashier \& Marsh, 2020; Epley \& Gilovich, 2016; Jerit \& Barabas, 2012). There is evidence for motivated reasoning in how individuals evaluate polls. Individuals reject poll results that go against their personally held opinions and desired political outcomes (Tsfati, 2001), and political attitudes become more polarized when individuals view polls that align with their prior attitudes (Madson \& Hillygus, 2019). The effect of motivated reasoning on 


\section{TRUST IN POLLS}

perceived poll credibility is also stronger among individuals with high levels of political knowledge (Kuru et al., 2017), further suggesting a relationship between ideological motives and reactions to poll results.

Another psychological explanation for distrust in polls is meta-cognitive reasoning: reasoning about the thoughts, attitudes, and motives of others. On this account, domain-general meta-cognitive concerns may arise independent of motivated processes, and therefore contribute to distrust in polls across contexts. One such meta-cognitive concern that may drive distrust in polls is perceptions that pollsters are biased. Trust in news media generally is affected by perceived ideological biases of media sources (Price \& Stroud, 2005; Searles et al., 2018), and early evidence suggests the credibility of a poll's source and its methods do affect trust in poll results (Kim et al., 2000; Salwen, 1987). But more recent work has found no evidence that methodological disclosures or ideological alignment with a poll's source affect individuals' trust in polls (Kuru et al., 2017). Another domain of meta-cognitive reasoning that plausibly contributes to distrust in polls is that individuals may not trust that poll respondents are honest. A prominent example of this concern is the oft-discussed "shy Trump voters" in 2016 (Connors et al., 2016) and 2020 (Yglesias, 2020). Some have questioned whether many such "shy" voters exist, and whether they explain Presidential Election polling errors (Prosser \& Mellon, 2018). But our concern is different. Is there a public perception that some voters are not honest to pollsters, and can it explain the perceived trustworthiness of polls about election outcomes?

We do not view motivated and meta-cognitive reasoning as rival explanations for distrust in polls, but rather wish to establish the independence of meta-cognitive reasoning in its association with distrust in polls. It is of little doubt that some meta-cognitive concerns arise as post-hoc justifications for motivated processes. This seems more likely when meta-cognitive 


\section{TRUST IN POLLS}

concerns are domain-specific (e.g., shy Trump voters). However, concerns over the honesty of poll respondents and the biases of pollsters may also be domain-general, and related to generalized distrust in the accuracy of polls regardless of the extent to which a poll and the direction of its inaccuracy aligns with one's desired outcome.

In this paper we present evidence for the following three claims. The first, for which we have the strongest evidence, is that meta-cognitive concerns regarding poll respondent honesty and pollster bias are consistently and strongly associated with distrust in polls. The second is that this association is independent of the relationship between motivated reasoning and distrust in polls. The third, for which the evidence is most tentative, is that meta-cognitive reasoning may be a better explanation for distrust in polls than motivated reasoning. Study 1 presents survey-based evidence that meta-cognitive concerns are associated with distrust in polls, and that this association is robust to (and larger than) the association between agreement with a poll's prediction and distrust (motivated reasoning). Study 2 presents survey-based evidence that the association between meta-cognitive concerns and distrust in polls persists in contexts where motivated reasoning cannot plausibly be present. Study 3 presents experimental evidence that meta-cognitive concerns and poll distrust are strongly associated with polling inaccuracy, and only weakly associated with whether polls pertain to races where the in-party won or lost, or whether a poll's inaccuracy is beneficial or detrimental to the in/out-party.

All stimuli, data, analyses presented below, and materials necessary for replication, can be found on the Open Science Framework for all studies (https://osf.io/cpx37). We preregistered the design, hypotheses, and confirmatory analyses for the pretest of Study 1

(https://osf.io/sn3x2), Study 1 (https://osf.io/et5ys), Study $2^{1}$ (https://osf.io/t78pg), and Study 3

\footnotetext{
${ }^{1}$ Chronologically, Study 2 was conducted after Study 3. They are presented non-chronologically here for narrative purposes, yet in their respective preregistrations they're referred to chronologically. As such, the preregistration for Study 2 herein is titled "Study 3" on the OSF, and vice versa. We apologize for any confusion this causes.
} 


\section{TRUST IN POLLS}

(https://osf.io/gb6hx). Sample sizes were determined a priori, and we report all measures. Open materials were prepared by the lead author; please do not hesitate to contact them if you have questions.

\section{Study 1}

In this study, we attempt to measure the unique association of several factors with people's trust of polling results using a representative set of polls across a diverse range of topics and organizations. We divide explanations of mistrust in polls into two broad categories: motivated reasoning and meta-cognitive reasoning. Motivated reasoning, in the context of polls, reflects the relationship between trust in a poll and agreement with or endorsement of the poll's results (Kuru et al., 2017; Madson \& Hillygus, 2019). Relatedly, we also examine the potential main effect of ideology on trust in polls, as American conservatives display lower levels of trust in the media in general (Middleton, 2018; Mourão et al., 2018). We also examine two distinct domains of meta-cognitive reasoning as it relates to trust in polls: the attribution that a given pollster is biased and untrustworthy, and the attribution that respondents to a given poll are dishonest.

Prior to conducting Study 1 we conducted a pilot test to ensure our measures of motivated and meta-cognitive reasoning displayed sufficient levels of internal reliability, and we conducted a pretest of our poll stimuli to ensure they were ideologically neutral in aggregate. See the Supplemental Materials for details on the measurement pilot and stimuli pretest.

\section{Method}

Study 1 involved participants viewing the 56 political and non-political polls from the pretest (which were politically neutral in aggregate, see Supplemental Materials) and responding 


\section{TRUST IN POLLS}

to the measures developed in the pilot. Data collection, analyses, and hypotheses were preregistered (https://osf.io/et5ys).

Participants: We recruited an online sample of 375 American participants (quota matched on age, gender, and race to census distributions) on October 29th, 2020, five days prior to the 2020 U.S. Presidential Election, on the Prolific survey platform (Palan \& Schitter, 2018). Participants were recruited for a 10 minute survey and were compensated \$2.20 USD. We received 381 completed responses and 30 participants failed the attention check, leaving a final $N=351\left(167\right.$ Male/2 non-binary, $M_{\text {Age }}=45.87, S D_{\text {Age }}=16.21$, Democrat $/ \mathrm{GOP} /$ Independent $=$ 182/76/93). This sample size, paired with the ten repeated measurements, was highly powered to detect our linear relationships of interest (Judd et al., 2012), and the sample size was chosen primarily to ensure each poll was viewed by $>60$ participants, such that mean values across polls could be reasonably compared.

Measures and Procedures: All participants provided informed consent to participate, and the study contained no deception. Participants were randomly assigned to see 10 of the 56 polls, and for each poll participants responded to eight survey items (order randomized, four reverse coded) along 1-7 Likert scales labeled "Strongly Disagree" to "Strongly Agree." These items captured the four judgments of interest: trust in the poll ("This poll's findings are credible/inaccurate(-)", $M=4.97, S D=1.38, \alpha=0.79)$, the perception that pollsters are unbiased ("These pollsters are trustworthy/biased(-)", $M=4.72, S D=1.45, \alpha=0.74$ ), the perception that poll respondents are honest ("The people who responded to this poll [reported their true feelings/were dishonest(-)]", $M=5.31, S D=1.23, \alpha=0.76)$, and agreement with the poll's results ("I share the opinion of the poll's majority" and "I hold the view expressed by the minority in the poll(-)", $M=4.71, S D=1.83, \alpha=0.76$ ) (the procedures were identical to the 


\section{TRUST IN POLLS}

pilot, see Supplemental Materials). After viewing the 10 polls participants responded to the attention check, demographic questions, and measures of economic/social ideology $\left(M_{\text {econ }}=3.42\right.$, $\left.S D_{\text {econ }}=1.82, M_{\text {social }}=3.03, S D_{\text {social }}=1.83\right)$.

\section{Study 1 Results}

All primary analyses were conducted using linear mixed-effects modeling via the lme4 package v. 1.1-29 (Bates et al., 2015) in R v. 4.2.1. All models utilized REML estimation, and degrees of freedom and $p$-values were computed using Welsh-Satterthwaite's approximation. To test our primary hypotheses we used maximally structured mixture models (Barr et al., 2013). Because poll stimuli were randomized across repeated measurements of participants' perceptions, our mixture models utilized fully crossed (i.e., independent/non-nested) random intercepts for participant and poll, and random slopes were modeled for all linear predictors within each random effect. Per our preregistered method for reducing model complexity when models were singular, we arrived at a model with random slopes for all three predictors modeled within-participant, but no random slopes modeled within-poll. We first regressed trust in polls on each of the predictors separately, then together in a single model. For each model we standardized all variables and derived estimates of variance explained ("Nakagawa's $\mathrm{R}^{2 "}$ ) (Nakagawa et al., 2017). Table 1 displays the results of these analyses. Our results support our primary hypothesis that motivated reasoning, perceptions of unbiased pollsters, perceived respondent honesty, are all positively associated with trust in polls.

Table 1: Predicting Trust in Polls

\begin{tabular}{|c|c|c|c|c|c|c|c|c|c|c|c|c|}
\hline \multirow[b]{2}{*}{ Predictors } & \multicolumn{3}{|c|}{ Model Polled } & \multicolumn{3}{|c|}{ Model Pollsters } & \multicolumn{3}{|c|}{ Model Motivated } & \multicolumn{3}{|c|}{ Full Model } \\
\hline & $\begin{array}{l}\text { Std. } \\
\text { Beta }\end{array}$ & $95 \% C I$ & $p$ & $\begin{array}{l}\text { Std. } \\
\text { Beta }\end{array}$ & $95 \% C I$ & $p$ & $\begin{array}{l}\text { Std. } \\
\text { Beta }\end{array}$ & $95 \% C I$ & $p$ & $\begin{array}{l}\text { Std. } \\
\text { Beta }\end{array}$ & $95 \% C I$ & $p$ \\
\hline
\end{tabular}


TRUST IN POLLS

\begin{tabular}{|c|c|c|c|c|c|c|c|c|c|c|c|c|}
\hline (Intercept) & -0.00 & $\begin{array}{c}-0.05- \\
0.05\end{array}$ & 0.930 & 0.02 & $\begin{array}{c}-0.03- \\
0.06\end{array}$ & 0.478 & 0.00 & $\begin{array}{c}-0.08- \\
0.08\end{array}$ & 0.948 & 0.01 & $\begin{array}{c}-0.03- \\
0.04\end{array}$ & 0.672 \\
\hline $\begin{array}{l}\text { Honest } \\
\text { Respondents }\end{array}$ & 0.64 & $\begin{array}{c}0.60- \\
0.67\end{array}$ & $<0.001$ & & & & & & & 0.36 & $\begin{array}{c}0.33- \\
0.40\end{array}$ & $<0.001$ \\
\hline $\begin{array}{l}\text { Unbiased } \\
\text { Pollsters }\end{array}$ & & & & 0.70 & $\begin{array}{c}0.66- \\
0.73\end{array}$ & $<0.001$ & & & & 0.45 & $\begin{array}{c}0.41- \\
0.48\end{array}$ & $<0.001$ \\
\hline $\begin{array}{l}\text { Agreement } \\
\text { with Results }\end{array}$ & & & & & & & 0.32 & $\begin{array}{c}0.28- \\
0.36\end{array}$ & $<0.001$ & 0.12 & $\begin{array}{c}0.10- \\
0.14\end{array}$ & $<0.001$ \\
\hline ICC & 0.30 & & & 0.29 & & & 0.50 & & & 0.28 & & \\
\hline \multirow[t]{2}{*}{$\mathrm{N}$} & $56_{\text {Poll }}$ & & & 56 Poll & & & $56_{\text {Poll }}$ & & & $56_{\text {Poll }}$ & & \\
\hline & $351_{\mathrm{ID}}$ & & & $351_{\mathrm{ID}}$ & & & $351_{\mathrm{ID}}$ & & & $351_{\mathrm{ID}}$ & & \\
\hline Observations & 3510 & & & 3510 & & & 3510 & & & 3510 & & \\
\hline $\begin{array}{l}\text { Marginal } \mathrm{R}^{2} / \\
\text { Conditional } \mathrm{R}^{2}\end{array}$ & $0.445 /$ & .610 & & $0.522 /$ & 0.661 & & 0.105 & 554 & & 0.651 & 49 & \\
\hline
\end{tabular}

Table 1: Mixed-effects regression models predicting trust in polls, with crossed random effects for participant and poll. All predictors and dependent variables are z-scores.

Next we examined whether participants' ideology and political party affiliation affected the associations observed in Table 1. Exploratory analyses examining the relationship of both economic and social ideology in tandem found that they were highly correlated at $r_{\text {Pearson }}=0.82$ $(p<0.001)$ and exhibited suppressor effects when both were entered as predictors with party affiliation. As such, we averaged the two measures into a single "Left-Right Ideology" measure $(M=3.22, \mathrm{SD}=1.75, \alpha=0.90)$ and used this measure throughout. This decision did not affect the results in any meaningful way compared to using the economic and social ideology measure separately. We entered political party affiliation (dummy coded, Democrat $=0$ ) and left-right ideology separately into the "Full Model" in Table 1, then included them in the model together. Table 2 displays the results of these analyses. We found that, when included together in the full model, left-right ideology was negatively associated with trust in polls but party affiliation was not. We also found that the inclusion of party affiliation and ideology did not meaningfully affect the relationships of our primary predictors and trust in polls.

Table 2: The Effects of Party and Ideology on Trust in Polls

\begin{tabular}{|c|c|c|c|c|c|c|c|c|c|}
\hline \multirow[b]{2}{*}{ Predictors } & \multicolumn{3}{|c|}{ Full Model: Party } & \multicolumn{3}{|c|}{ Full Model: Ideology } & \multicolumn{3}{|c|}{ Full Model: Ideology + Party } \\
\hline & $B$ & $95 \% C I$ & $p$ & $B$ & $95 \% C I$ & $p$ & $B$ & $95 \% C I$ & $p$ \\
\hline
\end{tabular}


TRUST IN POLLS

\begin{tabular}{|c|c|c|c|c|c|c|c|c|c|}
\hline (Intercept) & 0.03 & $-0.01-0.07$ & 0.169 & 0.00 & $-0.03-0.04$ & 0.802 & 0.00 & $-0.04-0.05$ & 0.983 \\
\hline \multicolumn{9}{|l|}{ Respondents } & $<0.001$ \\
\hline Unbiased Pollsters & 0.44 & $0.41-0.48$ & $<0.001$ & 0.44 & $0.41-0.48$ & $<0.001$ & 0.44 & $0.41-0.48$ & $<0.001$ \\
\hline $\begin{array}{l}\text { Agreement with } \\
\text { Results }\end{array}$ & 0.12 & \multicolumn{8}{|c|}{ Results } \\
\hline Party [Republican] & -0.08 & $\begin{array}{l}-0.14- \\
-0.01\end{array}$ & 0.018 & & & & -0.00 & $-0.10-0.09$ & 0.931 \\
\hline $\begin{array}{l}\text { Party } \\
\text { [Independent] }\end{array}$ & \multicolumn{2}{|c|}{ [Independent] } & 0.521 & & & & 0.02 & $-0.05-0.08$ & 0.618 \\
\hline $\begin{array}{l}\text { Left-Right } \\
\text { Ideology }\end{array}$ & & & & -0.04 & $\begin{array}{l}-0.07- \\
-0.01\end{array}$ & 0.004 & -0.04 & $\begin{array}{l}-0.08- \\
-0.00\end{array}$ & 0.039 \\
\hline $\mathrm{ICC}$ & 0.28 & & & 0.28 & & & 0.28 & & \\
\hline \multirow[t]{2}{*}{$\mathrm{N}$} & $56_{\text {Poll }}$ & & & $56_{\text {Poll }}$ & & & 56 Poll & & \\
\hline & $351_{\mathrm{ID}}$ & & & $351_{\mathrm{ID}}$ & & & $351_{\mathrm{ID}}$ & & \\
\hline Observations & 3510 & & & 3510 & & & 3510 & & \\
\hline $\begin{array}{l}\text { Marginal } \mathrm{R}^{2} / \\
\text { Conditional } \mathrm{R}^{2}\end{array}$ & 0.653 & 749 & & 0.654 & 51 & & $0.653 /$ & 751 & \\
\hline
\end{tabular}

Table 2: Mixed-effects regression models predicting trust in polls, with crossed random effects for participant and poll. All predictors and dependent variables are z-scores.

As party affiliation was not associated with trust in polls above ideology, we examined whether the "Full Model: Ideology" significantly improved model fit compared to the "Full Model" without the measure of ideology. We conducted a likelihood ratio test and found that the model which included left-right ideology significantly improved model fit compared to the model without ideology $\left(\chi^{2}(8)=17.2, p=0.028\right)$. Lastly, we examined the statistical assumptions of the "Full Model: Ideology" and found no evidence for multicollinearity (VIFs all <=2.12), observed homoscedasticity of variance, and observed normally distributed residuals and random effects, all suggesting our model met the assumptions of linear-mixed effects regression analyses.

\section{Discussion}

Our results provide compelling evidence that meta-cognitive reasoning about pollster bias and dishonest respondents are strongly associated with distrust in polls, regardless of whether their results are aligned with one's own attitudes. We also find tentative evidence that 


\section{TRUST IN POLLS}

meta-cognitive reasoning is more strongly associated with poll distrust than motivated reasoning and ideology. This interpretation is tentative because it is predicated on the assumption that in this context there is no causal relationship between motivated reasoning and the meta-cognitive concerns.

We do observe unique significant associations of motivated reasoning and ideology on trust in polls, but the observed associations are meaningfully smaller than the associations of meta-cognitive reasoning regarding pollster bias and respondent honesty. If motivated reasoning were a proximal cause of distrust in polls, we would expect to see a larger association between the two at baseline, equal to or larger than the observed associations between meta-cognitive reasoning and trust at baseline.

However, because the data from Study 1 are cross-sectional, there is one competing causal model that could potentially explain our results. That would be a model where motivated reasoning is a distal cause of distrust, but a proximal cause of meta-cognitive reasoning; in effect, people mistrust polls because they mistrust pollsters and poll respondents, but they mistrust pollsters and poll respondents because they expect pollsters and poll respondents not to agree with their own preferred opinions. This alternative model would potentially explain why the baseline association between trust and motivated reasoning was small, and why it diminished further when modeled with meta-cognitive reasoning. To address this competing hypothesis, we designed and implemented Study 2.

\section{Study 2}

In a preregistered study (https://osf.io/t78pg), we attempt to design stimuli where motivated reasoning cannot plausibly play a role in driving trust in polls, and so if there is a relationship between distrust in polls and meta-cognitive concerns, it could not be explained by 


\section{TRUST IN POLLS}

prior attitudes exerting first-order causal effects on trust and/or meta-cognitive reasoning. We do this with the same design as Study 1, but we present participants from the United States with polls from foreign elections and with fictional polls for which respondents would not plausibly have any prior allegiance or attitude, positive or negative. The foreign election polls include a 2021 Armenian parliamentary election poll, a 2022 Northern Ireland Assembly poll, a 2020 Mongolian parliamentary election poll, and a 2020 Peruvian parliamentary election poll. These polls were chosen because they did not contain any party names which conveyed clear ideological information the average American participant would recognize (e.g., there were no "Socialist" parties), which would have potentially induced motivated perceptions. The fictional polls includes a provincial election poll from the "nation of Marcona," a poll for the first democratic election among human colonists on the planet Mars, a poll for general elections in the “country of Arteez," and a poll for the first parliamentary election in the formerly monarchical "island nation of Fiso Liapa."

The goal of including both real polls from foreign elections and fictional polls was that while stronger assumptions of a lack of prior preferences can be made for the fictional polls, their artificiality may affect response in a way that would be unobservable without the ability to compare responses to the foreign election polls.

\section{Method}

Participants: We preregistered (https://osf.io/t78pg) the collection of 200 American participants on the survey recruitment platform Prolific (Palan \& Schitter, 2018), which based on a priori sensitivity analyses is powered at $80 \%$ to detect mean differences of $d=0.17$ and linear relationships of $\beta=0.034$ (with eight repeated measures and a repeated measures correction of 0.21, which is based on pilot data). Participants were compensated \$1.20 USD for a 6 minute 


\section{TRUST IN POLLS}

survey. Eight of the 200 recruited participants failed the attention check and were excluded from all analyses, leaving a final $N=192$ (98 Male/91 Female/3 non-binary or unlisted, $M_{\text {age }}=38.47$, $\left.S D_{\text {age }}=13.48\right)$. Data were collected in April of 2022.

Measures and Procedures: All participants provided informed consent to participate, and the study contained no deception. Participants were randomly assigned to either view the four foreign polls or four fictitious polls first, and within block the order of the four polls was randomized. Before each block participants were given instructions which read "On the following pages you will read the results of 4 different polls from [countries around the world/fictional places]. You will be asked for your perceptions of the polls. Because the polls are [from foreign countries/intentionally fictional], you may feel like they are hard to judge. That's okay! In cases like that, we encourage you to go with your gut feeling. We sincerely appreciate your time and effort, -The Research Team." For each poll, participants read a description of the election and poll, and saw the predicted percentage of the vote going to each party. Below the poll, participants responded to the trust $(M=4.87, S D=1.31)$ and perceived respondent honesty $(M=5.14, S D=1.18)$ from Study 1, order randomized. Lastly, participants responded to basic demographic questions, and the survey ended.

\section{Results}

Table 3 includes the means and standard deviations for the dependent variables on all polls. All primary analyses were conducted using linear mixed-effects modeling via the lme4 package v. 1.1-29 (Bates et al., 2015) in R v. 4.2.1. All models utilized REML estimation, and degrees of freedom and $p$-values were computed using Welsh-Satterthwaite's approximation. Per the preregistration, to test our primary hypotheses we used maximal structured mixture models (Barr et al., 2013) with crossed random intercepts for participant and poll and random slopes 


\section{TRUST IN POLLS}

modeled for predictors with within-cluster variance ${ }^{2}$ (i.e., perceived respondent honesty within person and poll, and condition [fake/foreign poll] within person).

Table 3

\begin{tabular}{|l|l|l|}
\hline \multicolumn{1}{|c|}{ Poll } & Mean Perceived Honesty (SD) & \multicolumn{1}{c|}{ Mean Trust (SD) } \\
\hline Armenia (Real) & $5.07(1.12)$ & $4.84(1.26)$ \\
\hline Arteez (Fictional) & $5.25(1.22)$ & $5.03(1.30)$ \\
\hline Fiso (Fictional) & $5.08(1.15)$ & $4.79(1.21)$ \\
\hline Marcona (Fictional) & $5.21(1.10)$ & $5.00(1.20)$ \\
\hline Mongolia (Real) & $5.11(1.16)$ & $4.87(1.29)$ \\
\hline Northern Ireland (Real) & $5.25(1.15)$ & $5.04(1.19)$ \\
\hline Peru (Real) & $4.90(1.21)$ & $4.45(1.43)$ \\
\hline Mars (Fictional) & $5.22(1.32)$ & $4.94(1.46)$ \\
\hline
\end{tabular}

Table 3: Means and standard deviations of dependent variables by poll stimuli.

We began by examining whether condition (fake vs. real polls) affected trust and perceived respondent honesty. Compared to fake polls, real polls were not seen as more or less trustworthy $(\beta=-0.11, p=0.354)$, nor were respondents perceived as more or less honest $(\beta=$ $-0.09, p=0.250)$. We then examined the linear association between trust and perceived respondent honesty and, as hypothesized, observed a significant positive association $(\beta=0.71, p$ $<0.001)$, replicating the association and approximate effect size observed in Study $1(\beta=0.64)$. Lastly, we interacted condition with perceived respondent honesty in predicting trust to examine whether the association between trust and perceived respondent honesty differed by real vs. fake polls. The interaction was not significant $(\beta=0.00, p=0.839)$, and the slope estimate between trust and perceived respondent honesty did not change $(\beta=0.71, p<0.001)$.

Given that a conceit of this study was that participants would have no prior attitudes regarding these polls, a potential concern is that participants may respond in a way reflective of having no opinion about trust or perceived respondent honesty. Operationally, this would correspond to answering " 4 " (the midpoint) on the bi-polar 1-7 Likert scales labeled "Strongly

\footnotetext{
${ }^{2}$ The preregistration for Study 2 erroneously characterized what variables have within-cluster variation. Condition has variance within-person, not poll, and perceived respondent honesty have variance in person and poll.
} 


\section{TRUST IN POLLS}

Disagree" to "Strongly Agree." As can been seen on Table 4 however, examining mean, median, and modal responses does not suggest many participants are responding with " 4 " to the polls. In fact, the only instance where the modal response is 4 is for the foreign polls, not the fictional polls where this concern is theoretically more present.

Table 4

\begin{tabular}{|l|c|c|c|c|}
\hline \multirow{2}{*}{ Mean } & \multicolumn{2}{|c|}{ Foreign Polls } & \multicolumn{2}{c|}{ Fictional Polls } \\
\cline { 2 - 5 } & Trust & Perceived Honesty & Trust & Perceived Honesty \\
\hline Median & 4.80 & 5.08 & 4.94 & 5.19 \\
\hline Mode & 5 & 5 & 5 & 5.5 \\
\hline
\end{tabular}

Table 4: Mean, median, and model Likert responses (all 1-7 scales) by dependent variable and fictional/foreign polls.

\section{Discussion}

As hypothesized, we observed a significant positive linear association between trust and perceived respondent honesty in a context where prior preferences could not plausibly affect perceptions, meaning there is no reasonable account of motivated reasoning being the underlying cause of the observed association. Our observed association size was very similar to that observed in Study $1(\beta=0.71$ vs. 0.64$)$. Moreover, perceptions of the fictional polls were statistically indistinguishable from perceptions of the foreign polls, all suggesting that any artificiality of reading fictional polls from fictional polities did not affect the association between trust and meta-cognitive concerns. Indeed, trust in the (real) polls from Study 1 was 4.97, and trust in the fictional polls from Study 2 was 4.94. The patterns observed in Study 2 match those in Study 1, all suggesting that meta-cognitive concerns about polls are generalized concerns that individuals share across the polls they encounter, independent of motivated responses to the content of polls. 


\section{TRUST IN POLLS}

\section{Study 3}

In a preregistered study (https://osf.io/gb6hx), we examine how learning whether a political poll was accurate or inaccurate in its forecast of a 2020 US Senate or House race affected perceived trust in the poll, perceived pollster bias, and perceived respondent honesty. All participants viewed six polls from the poll aggregation website www.FiveThirtyEight.com (“538”). Each poll corresponded to one of six conditions ( $3 \times 2$ within-subjects design): a poll which either overestimated, underestimated, or accurately predicted a Democrat or Republican victory. Over/underestimation was operationalized as a $>5$ percentage point error (polls varied from 5.08 to 23.2 percentage point errors); and accuracy was operationalized as $<4$ percentage point errors (polls ranged from 3.26 to 0.22 percentage point errors). Participants were told the poll's sample size, the pollster which conducted the poll, the race (Senate or House) and State, the party of the projected winner and their projected winning percentage gap. All this information was available in the image of the poll on 538. Additionally, participants were given the following new information. They were informed of the actual win percentage, whether the poll therefore under- or overestimated the winner's vote percentage, and the exact difference between the projected and actual win percentage (e.g., "The poll predicted the Democrat would win by 2 percentage points. The Democrat ultimately won by 9.18 percentage points. As such, the poll under-estimated the outcome by 7.18 percentage points"). Lastly, on every page participants were informed of the average polling errors for House or Senate polls in 2020, based on analyses from 538. Participants were also asked how inaccurate they perceived the poll to be, as a manipulation check. The sample of participants included an equal number of self-identified Republicans, Democrats, and Independents. All participants indicated their strength of party identification, and Independents indicated whether they leaned toward one party. 


\section{TRUST IN POLLS}

Study 3 was designed to allow participants multiple and independent ways to engage in motivated reasoning, and to benchmark any observed motivated reasoning against veridical reasoning in response to the polls, all within-subjects. "Veridical" reasoning here was operationalized as perceiving inaccurate polls as less trustworthy and expressing greater concerns over respondent honesty and pollster bias relative to accurate polls. The juxtaposition between motivated and veridical reasoning draws from seminal theorizing on the psychology of motivated reasoning, namely that processing information pursuant to a desired outcome (motivated reasoning) stands opposite to the goal of perceiving the world accurately (Kunda, 1990).

There were three distinct ways participants could have motivated responses to the polls in Study 3. The first is the simplest form of motivated reasoning, which we call the "Loser Effect." The Loser Effect would predict that all else equal, participants will view polls which correctly predict in-party losses more negatively than polls which correctly predict in-party victories, due to the negative affect associated with in-party losses/out-party victories. The second and third ways participants could engage in motivated reasoning were distinct, but not mutually exclusive, from the Loser Effect. We call these the "Win-Less" and "Lose-More" Effects, which capture the idea that polling inaccuracies can induce expectancy violations, both positive and negative, when the true outcome is known, and that negative expectancy violations will lead to greater penalty.

The Win-Less Effect would predict that participants will penalize polls which overestimate the winning vote percentage of an in-party candidate. For example, imagine a Democrat viewing two polls for two races, both predicting a Democratic win by 10 percentage points, yet the final outcomes are a 5 percentage point win and a 15 percentage point win for Democrats. Both polls (1) forecasted an in-party candidate victory, and (2) had equal sized error. 


\section{TRUST IN POLLS}

However, in the race where a Democrat won by 5 percentage points, Democratic participants would experience a negative expectancy violation because their in-party candidate won by less than forecasted, relative to the race where the outcome was a 15 percentage point win. In such a case, a motivated reasoner would penalize the poll which overestimates the win percentage relative to the underestimating poll. The "Lose-More" Effect predicts the same pattern, in the reverse direction, for polls predicting in-party loses, such that polls which underestimate out-party victory margins would be penalized more.

\section{Method}

Participants: We preregistered (https://osf.io/gb6hx) a target convenience sample size of $N=495$ based on a power analysis of the sample needed to detect with $80 \%$ power an effect size of $d=0.2$ for a 3 (between, Participant Party ID) x 2 (within, Party ID of Election Winner) x 3 (within, Poll Inaccuracy) fixed effect interaction in a repeated measures mixture model. Participants were compensated \$1.25 USD for a 6 minute study. We collected 527 participants on the Prolific survey platform (Palan \& Schitter, 2018) and removed 29 participants (5.5\% of the sample) who failed the preregistered attention check, leaving a final $N=498$ (264 Male/11 non-binary/unlisted, $\left.M_{\text {age }}=33.76, S D_{\text {age }}=11.61\right)$ We used the prescreen function on Prolific to collect an even distribution of partisans (final sample: Democrat $/$ Republican/Independent $=$ 171/164/163). Data were collected in July 2021.

Measures and Procedures: All participants provided informed consent to participate, and the study contained no deception. Participants were first given instructions that they would be viewing polls which forecasted 2020 US House and Senate elections alongside information about the actual outcomes of those elections. Next participants viewed six polls in random order, one for each condition (accurate/overestimated/underestimated x Democrat win/Republican 


\section{TRUST IN POLLS}

win). Within each of the six conditions, participants were randomized to one of three polls that fit the condition (e.g., all participants viewed one of three polls where a Republican victory was overestimated, etc.). This was done to reduce potential biases related to the constraints of using real polls, for example it was impossible to match polls on many attributes across conditions (e.g., sample size, the date the poll was conducted, the exact magnitude of inaccuracy, etc.) The process of choosing the 18 polls is detailed extensively in the preregistration (https://osf.io/gb6hx). This design, where participant and stimuli are fully crossed, participant and condition are fully crossed, and stimuli is nested within condition, is referred to as a " $\mathrm{CNC}$ Design" and detailed further by Judd, Westfall, \& Kenny (2017).

Participants rated each poll on the primary dependent variables, all on 1-7 Likert items anchored on "Strongly Disagree" (1) to "Strongly Agree" (7): a two-item measure of trust in the findings ("This poll's findings were untrustworthy(-)/credible", $M=4.65, S D=1.55, \alpha=0.69$ ), a two-item measure of perceived unbiased pollsters ("These pollsters were biased(-)/trustworthy", $M=4.64, S D=1.39, \alpha=0.83$ ), a two-item measure of perceived respondent honesty ("The people who responded to this poll [were dishonest(-)/reported their true feelings/opinions]", $M=$ 4.94, $S D=1.33, \alpha=0.73$ ), and a single item manipulation check of perceived accuracy ("This poll's findings are inaccurate", $M=3.59, S D=1.83$ ).

After rating the six polls, participants responded to an attention check which asked "Please, in the box below, write out the answer to the following math problem, capitalizing the first letter of your answer (e.g. "Eight", not "eight" or "8”). What does one plus three equal?" Participants who did not respond with "Four" were excluded from all analyses. Participants then responded to the measure of party identification strength from the 2016 American National Elections Survey (ANES; www.electionstudies.org). Lastly participants responded to 


\section{TRUST IN POLLS}

demographic questions, self-reported social ideology $(M=3.54, S D=1.98)$ and economic ideology $(M=3.93, S D=1.96)$, both on 1-7 Likert items anchored on "Very Liberal" (1) to "Very Conservative" (7). Participants were given an opportunity to provide an open comment, then the study ended.

\section{Results}

See Table 5 for variable means and standard deviations by condition, and Table 6 details the extent to which the findings support veridical vs. motivated reasoning accounts. All primary analyses were conducted using linear mixed-effects modeling via the lme4 package v. 1.1-29 (Bates et al., 2015) in R v. 4.2.1, with crossed random intercepts for participant and for poll stimuli $^{3}$. All models utilized REML estimation, and degrees of freedom and $p$-values were computed using Welsh-Satterthwaite's approximation. All factor variables were sum coded in the regressions, and all pairwise comparisons utilized Bonferroni $p$-value corrections.

As a manipulation check, participants were asked how much they disagree/agree that “This poll's findings were inaccurate". We observed large main effects of poll-condition, where accurate polls $(M=2.64, S D=1.61)$ were perceived as significantly more accurate than overestimating poll $(M=3.95, S D=1.74, p=0.005, \beta=0.72)$ and more accurate than underestimating poll $(M=4.17, S D=1.75, p=0.001, \beta=0.87)$. There were no significant main effects of either respondent party affiliation or party of the winner on perceived inaccuracy.

Veridical Reasoning: We found strong support for veridical reasoning, such that inaccurate polls were seen as less trustworthy and of greater meta-cognitive concern than accurate polls. Perceived trust in the poll's findings was significantly higher for accurate polls $(M$ $=5.45, S D=1.30)$ than for overestimating polls $(M=4.35, S D=1.50, p=0.005, \beta=0.76)$ and 
TRUST IN POLLS

underestimating polls $(M=4.13, S D=1.50, p=0.002, \beta=0.89)$. Overestimating polls were not perceived as more trustworthy than underestimating polls $(\beta=0.13, p=1.00)$. The perception that the poll's pollsters were unbiased was significantly higher for accurate polls $(M=5.22, S D=$ 1.30) than for overestimating poll $(M=4.42, S D=1.34, p=0.003, \beta=0.62)$ and underestimating polls $(M=4.28, S D=1.34, p=0.001, \beta=0.71)$. Pollsters of overestimating polls were not perceived as more or less biased than pollsters of underestimating polls $(\beta=0.09$, $p=1.00)$. The perception that the poll's respondents were honest was significantly higher for accurate polls $(M=5.45, S D=1.21)$ than for overestimating poll $(M=4.73, S D=1.29, p=$ $0.003, \beta=0.57)$ and underestimating polls $(M=4.64, S D=1.33, p=0.001, \beta=0.62)$. Perceived respondent honesty did not differ between over- and underestimating polls $(\beta=0.05, p=1.00)$.

See Supplemental Table S1 for the full models from which these pairwise contrasts were computed. We also examined the statistical assumptions of the three models above and found no evidence for multicollinearity, observed homoscedasticity of variance, and observed normally distributed residuals and random effects, all suggesting our models met the assumptions of linear-mixed effects regression analyses.

Table 5

\begin{tabular}{|l|l|l|l|l|l|}
\hline Poll Condition & Race Winner & $\begin{array}{c}\text { Honest } \\
\text { Respondents } \\
\text { Mean (SD) }\end{array}$ & $\begin{array}{c}\text { Unbiased Pollster } \\
\text { Mean (SD) }\end{array}$ & $\begin{array}{c}\text { Trust in Poll } \\
\text { Mean (SD) }\end{array}$ & $\begin{array}{c}\text { Perceived } \\
\text { Inaccuracy Mean } \\
\text { (SD) }\end{array}$ \\
\hline Accurate & Democrat & $5.48(1.20)$ & $5.21(1.34)$ & $5.46(1.29)$ & $2.64(1.64)$ \\
\hline Accurate & Republican & $5.42(1.22)$ & $5.23(1.26)$ & $5.44(1.31)$ & $2.64(1.58)$ \\
\hline Overestimated & Democrat & $4.70(1.28)$ & $4.35(1.36)$ & $4.27(1.47)$ & $4.07(1.72)$ \\
\hline Overestimated & Republican & $4.77(1.31)$ & $4.50(1.33)$ & $4.44(1.52)$ & $3.84(1.75)$ \\
\hline Underestimated & Democrat & $4.68(1.34)$ & $4.32(1.37)$ & $4.17(1.57)$ & $4.15(1.84)$ \\
\hline Underestimated & Republican & $4.60(1.33)$ & $4.23(1.30)$ & $4.10(1.43)$ & $4.20(1.66)$ \\
\hline
\end{tabular}

Table 5: Means and standard deviations for the dependent variables by poll condition and party of winner.

Motivated Reactions: Overall we found little evidence that participants engaged in motivated reasoning. If partisans were engaging in motivated reasoning, we would expect to see 
TRUST IN POLLS

at least one of the Loser Effect, the Win-Less effect, or the Lose-More Effect. Table 6 summarizes our findings.

Table 6

\begin{tabular}{|l|l|}
\hline \multicolumn{1}{|c|}{ Possible Patterns of Trust/Meta-Cognitive Reasoning } & \multicolumn{1}{c|}{ Supporting Evidence } \\
\hline Veridical Reasoning Effects & \\
\hline $\begin{array}{l}\text { Wrong: Polls are penalized for being inaccurate vs. accurate in } \\
\text { predicted win/lose percentages }\end{array}$ & Strong Evidence \\
\hline Motivated Reasoning Effects & Weak Evidence \\
\hline $\begin{array}{l}\text { Loser: Polls are penalized for accurately forecasting in-party loss } \\
\text { (vs. accurately forecasting in-party victory) }\end{array}$ & No Evidence \\
\hline $\begin{array}{l}\text { Win-Less: Polls are penalized for overestimating in-party victory } \\
\text { margin (vs. underestimating victory margin) }\end{array}$ & No Evidence \\
\hline $\begin{array}{l}\text { Lose-More: Polls are penalized for underestimating out-party } \\
\text { victory margin (vs. overestimating loss margin) }\end{array}$ & \\
\hline
\end{tabular}

Loser Effect: We found weak support for a "Loser Effect" across poll trust or meta-cognitive concerns. Among Republicans and Republican-leaning Independents, there was no difference in trust toward polls predicting Democratic $(M=4.51, S D=1.58)$ relative to Republican victories $(M=4.66, S D=1.55, p=0.632, \beta=-0.08)$, nor in perceived pollster bias across Democratic $(M=4.46, S D=1.39)$ relative to Republican victories $(M=4.62, S D=1.34$, $p=0.398, \beta=-0.11)$ or perceived respondent honesty across Democratic $(M=4.81, S D=1.31)$ relative to Republican victories $(M=4.91, S D=1.30, p=0.538, \beta=-0.07)$. A nearly identical pattern was observed for Democrats and Democratic-leaning Independents. There was no difference in trust toward polls predicting Democratic $(M=4.79, S D=1.48)$ relative to Republican victories $(M=4.69, S D=1.49, p=0.749, \beta=0.05)$, nor in perceived pollster bias across Democratic $(M=4.79, S D=1.39)$ relative to Republican victories $(M=4.62, S D=1.34$, 
TRUST IN POLLS

$p=0.650, \beta=0.06)$ or perceived respondent honesty across Democratic $(M=5.08, S D=1.28)$

relative to Republican victories $(M=4.97, S D=1.32, p=0.484, \beta=0.08)$. See Supplemental

Table S1 for full model statistics. In summary, we find no evidence for motivated reasoning in the form of a "Loser Effect" in the fully specified models described above.

Because a null Loser Effect supports our theorizing, we attempted to "find" a Loser Effect by engaging in non-conservative model specifications. We collapsed the three conditions into two (accurate vs. inaccurate polls), and collapsed across political parties and created a single binary variable for whether the participant's in-party or out-party won the race of the poll. In mixture models with these two binary variables as fixed effects, with no interaction, we observed statistically significant Loser Effects, where polls predicting in-party victories were trusted more $(M=4.73, S D=1.51)$ than polls predicting in-party losses $(M=4.61, S D=1.53, p=0.020, \beta=$ -0.07). The same pattern emerged when meta-cognitive concerns were modeled with this approach. Pollsters predicting in-party victories were seen as more unbiased $(M=4.71, S D=$ 1.37) than pollsters predicting in-party losses $(M=4.59, S D=1.38, p=0.03, \beta=-0.08)$, and polls predicting in-party victories were as having more honest respondents $(M=5.01, S D=1.29)$ than polls predicting in-party losses $(M=4.90, S D=1.32, p=0.006, \beta=-0.07)$. Whether or not the Loser Effect was robust to more appropriate model specifications (modeling all three conditions, controlling for party identification, modeling interactions, etc.), and across dependent variables, varied considerably. As such, we argue this is weak evidence for the Loser Effect, and that if it is real the effect size is very small.

Win-Less Effect \& Lose-More Effect: We found no evidence for the "Win-Less" Effect or the "Lose-More" Effect. Not a single condition/party contrast testing either of these effects was statistically significant. As with the "Loser Effect," null results support our theorizing, so we 


\section{TRUST IN POLLS}

attempted to "find" a Win-Less Effect and Lose-More Effect by engaging in non-conservative model specifications. All attempts yielded further null results. See Supplemental Materials for complete analyses.

Partisanship and Ideology: We found relatively consistent evidence that Republicans and conservatives had more negative reactions to polls than Democrats and Liberals, however neither partisan identification or ideology ever significantly interacted with Condition (see Supplemental Materials for full results).

\section{Discussion}

Our results provide clear evidence for veridical reasoning in reactions to polling inaccuracy. Because all participants viewed the same distribution of accurate and inaccurate polls, and participants were always anchored on an estimate of the true mean polling error for 2020 House and Senate election polls, we can be relatively confident the observed effects were driven by judgments of relative inaccuracy versus the possibility of individuals possessing an $a$ priori expectation that polls be perfectly accurate. These large effects of veridical reasoning stand in contrast to the minimal evidence we found for motivated responding. The only evidence we found for any motivated reasoning was weak evidence for the Loser Effect, where participants penalized polls which correctly predicted out-party victories relative to those which correctly predicted in-party victories. We argue that this evidence is weak because the Loser Effect was only consistently observed when intentionally engaging in non-conservative model specifications. Conversely, we found no evidence for the Win-Less or Lose-More Effects. In summary, we found that trust in polls and generalized meta-cognitive concerns about polls were highly sensitive to poll accuracy and largely insensitive to one's partisan motivations. 


\section{TRUST IN POLLS}

\section{General Discussion}

Studies 1-3 provide compelling evidence that meta-cognitive concerns about biased pollsters and dishonest poll respondents are associated with public mistrust in polls, and that this association is independent of motivated reasoning. Our work builds upon the nascent literature on public distrust in polls (Kuru et al., 2017; Madson \& Hillygus, 2019) by not only investigating a wider range of factors that might explain distrust in polls, including motivated reasoning, veridical reasoning, meta-cognitive concerns, and ideology, but also by explicating the relative strength of those associations. Study 1 suggests that the hitherto unstudied attribution of respondent dishonesty, and previously discounted effect of perceptions of poll source credibility (Kuru et al., 2017), in fact play a larger role in poll distrust. Study 2 shows that motivated reasoning and meta-cognitive concerns can be wholly independent, where the latter does not necessarily stem from the former. Even in fictional polls, where respondents have no prior preferences or allegiance to motivate any kind of reasoning, they still think that some people who respond to polls are dishonest, and this attribution is strongly associated with distrust in the fictional polls. Study 3 provides further evidence that meta-cognitive concerns are largely independent from motivated reasoning, and instead sensitive to veridical reasoning. Learning that a poll's predictions were inaccurate caused a large decrease in trust, perceived respondent honesty, and the perception the pollsters were unbiased. Conversely, polls which favored the in-party were rarely viewed as higher in trust and lower in pollster bias and respondent dishonesty than polls which favored the out-party. Partisans were presented with multiple such opportunities to engage in motivated reasoning, yet their perceptions of trust and their meta-cognitive concerns followed patterns of veridical reasoning. 


\section{TRUST IN POLLS}

The strength of our findings lie in their generalizability. Study 1 was conducted with a sample quota-matched to census demographics of American adults, and we pursued and validated a large, representative set of naturally presented poll stimuli. We also modeled random assignment to stimuli as random intercepts (with random slopes for linear predictors), providing greater generalizability to how people respond to myriad polls in the real-world. Past work has understandably looked primarily at political polls, and typically a small set in any given study, but such methodologies make generalizable inferences regarding how individuals perceive polling information difficult. Study 3 also used a generalizable methodology by selecting on multiple instances of real-world polling inaccuracies, across differing States and races, and used stimuli taken from a highly popular poll aggregation website (www.FiveThirtyEight.com). By also clearly providing participants with information about the extent of each poll's inaccuracy, as one might find in a news article reporting on election results, we ensured that participants' experience was similar to how they might learn of a poll's inaccuracy predicting in the real world. One strength of Study 2 is that it serves as a strong test against an alternative explanation of our findings in Study 1, namely, that psychologically, meta-cognitive concerns and trust judgments all stem from a common source, namely motivated reactions to the polls, predicated on peoples' prior attitudes and desired outcomes. We saw no plausible way our participants would have prior attitudes about fictional people, places, and political parties lacking ideological markers.

\section{Limitations \& Future Directions}

Studies 1-3 had several limitations which illuminate promising areas of future research on distrust in polls. One explanation unexplored here is that people distrust polls because they violate non-ideological prior beliefs. This possibility relates to questions of Bayesian updating in 


\section{TRUST IN POLLS}

the understanding of political information (Hill, 2017), and is a potential factor unexplored by the current research. Similarly, it may be the case that individuals have intuitions about the relative strength of the attitudes of poll respondents that affect trust in polls. For example, individuals may believe that many people's political attitudes are weakly held and likely to change post-responding to a poll, therefore driving distrust in polls by way of temporal discounting.

A limitation inherent in our generalizable designs of Studies 1 and 2 is the inability to disentangle the specific ways in which people meta-cognitively reason about pollsters and poll respondents. For example, attributions of pollster "bias" may relate to perceived ideological biases or to perceived methodological biases (e.g., people may attribute selection biases to polls, or distrust complex statistical techniques). Similarly, perceived respondent dishonesty may be driven by the perceptions that most respondents are dishonest, or conversely that a specific and small subset of respondents are dishonest. Individuals may attribute socially desirable responses to poll participants, or they may attribute cheerleading effects where partisans over-report support for in-party politicians and policies. These points bring up a critical consideration when interpreting our results: individuals may be accurate in their meta-cognitive attributions. There is no doubt that many pollsters are indeed ideologically biased, and phenomena such as socially desirable responding and the cheerleading effect in polls are real (Bullock \& Lenz, 2019). Therefore, meta-cognitive concerns may arise, in part, from relatively accurate assessments of the motives of pollsters and poll respondents.

One limitation of in Study 3 is that none of the inaccurate polls predicted the wrong winner, they only over- or underestimated the eventual winner's win percentage. This decision reflected the need to reduce the complexity of the experiment. However, it is possible that 


\section{TRUST IN POLLS}

participants would react in a more motivated fashion if a poll predicted an in-party win but one's in-party lost compared to a poll which predicted an out-party win when one's in-party ultimately won. Similarly, Study 3 may not have observed motivated reasoning because it involved evaluating polls ex post, where election outcomes and associated poll accuracy are clearly known. It is plausible that the affective processes which theoretically drive motivated reasoning are present only ex ante and associated with anticipatory emotions related to pending election outcomes. However, it is highly implausible that motivated reasoning toward polls is both a discrete ex ante phenomenon which vanishes post-election, and a phenomenon which has a durable, generalized causal effect on downstream meta-cognitive concerns. As such, we argue that Study 3 provides compelling evidence for the independence of meta-cognitive reasoning and motivated reasoning.

Relative to Studies 1 and 3, Study 2's use of entirely fictional polls limits its generalizability to other contexts. The goal of Study 2 was to provide a strong test against an alternative explanation for our pattern of results, not to model generalizable associations related to judgments of polls, the polled, the pollsters (despite using the same method at Study 1). And while we observed nearly identical patterns of responding, and nearly identical associations between trust and meta-cognitive concerns, across Study 1 and Study 2's fictional and real polls, we hesitate to make strong inferences about identical psychological processes underlying these similar patterns.

If people can accurately assess the extent to which poll respondents are dishonest, one possible explanation is that people may be considering how they themselves might be dishonest on a poll (or feel social pressure to be dishonest), and then attributing those same considerations onto other poll respondents. This dynamic would be an instance of projection/assumed similarity, 
TRUST IN POLLS

a widely observed process in social perception (Ames, 2004; Cho \& Knowles, 2013; Holtz \& Norman, 1985). If this is occurring, then the actual extent of dishonesty in poll responses can be indirectly measured by the extent to which individuals project such dishonesty, and may itself serve to make polls more accurate.

\section{Conclusion}

Across three studies we argue that meta-cognitive reasoning regarding the bias of pollsters and dishonesty of poll respondents is independent from motivated reasoning and ideology. Our findings illustrate that such meta-cognitive concerns are significant predictors of poll distrust, and highly sensitive to the accuracy of polling predictions. Our findings also raise questions regarding how strong a role motivated reasoning plays in poll distrust. In summary, we explicate a largely unstudied correlate of public distrust in polling results, highlight the importance of considering meta-cognitive reasoning relative to motivated reasoning when studying the processing of political information, and inform ongoing discussions of how the widespread perception of polling failures in the 2016 and 2020 U.S. Presidential Elections may affect public perceptions of poll findings, pollsters, and poll respondents. 
TRUST IN POLLS

\section{Acknowledgments}

We wish to thank Andrei Cimpian for his involvement with early iterations of this research, Daniel Yudkin for connecting members of the current research team, and the Sidanius Lab for their feedback on the results of Study 1.

\section{Funding}

The research was generously funded by the Eleanor Nims Brink Fund at Vassar College, and a School of Arts and Sciences University Research Fellowship and Research Opportunity Grant at the University of Pennsylvania. Funds were utilized to compensate survey participants.

\section{Ethics}

This research was approved by the University of Pennsylvania's Institutional Review Board under protocol \#833532. All participants provided informed consent to participate, and no deception was utilized in this study.

\section{Contributions}

All authors contributed to the generation of the research questions and study designs, and all authors contributed to the drafting of the manuscript. JL and SP prepared the online surveys, and JL facilitated the preregistrations, data collection, analyses, and public posting of materials. 
TRUST IN POLLS

\section{References}

Ames, D. R. (2004). Strategies for social inference: A similarity contingency model of projection and stereotyping in attribute prevalence estimates. Journal of Personality and Social Psychology, 87(5), 573-585. https://doi.org/10.1037/0022-3514.87.5.573

Barr, D. J., Levy, R., Scheepers, C., \& Tily, H. J. (2013). Random effects structure for confirmatory hypothesis testing: Keep it maximal. Journal of Memory and Language, 68(3), 255-278. https://doi.org/10.1016/j.jml.2012.11.001

Bates, D., Maechler, M., Bolker, B., \& Walker, S. (2015). Fitting linear mixed-effects models using lme4. Journal of Statistical Software, 67(1), 1-48. https://doi.org/10.18637/jss.v067.i01

Brashier, N. M., \& Marsh, E. J. (2020). Judging truth. Annual Review of Psychology, 71, $499-515$.

Bullock, J. G., \& Lenz, G. (2019). Partisan bias in surveys. Annual Review of Political Science, $22,325-342$.

Cho, J. C., \& Knowles, E. D. (2013). I'm like you and you're like me: Social projection and self-stereotyping both help explain self-other correspondence. Journal of Personality and Social Psychology, 104(3), 444-456. https://doi.org/10.1037/a0031017

Cohn, N. (2020, November 10). What went wrong with polling? Some early theories. The New York Times. https://www.nytimes.com/2020/11/10/upshot/polls-what-went-wrong.html

Connors, E., Klar, S., \& Krupnikov, Y. (2016, November 12). There may have been shy Trump supporters after all. The Washington Post. https://www.washingtonpost.com/news/monkey-cage/wp/2016/11/12/there-may-have-bee n-shy-trump-supporters-after-all/

Epley, N., \& Gilovich, T. (2016). The mechanics of motivated reasoning. Journal of Economic 


\section{TRUST IN POLLS}

Perspectives, 30(3), 133-140. https://doi.org/10.1257/jep.30.3.133

Hill, S. J. (2017). Learning together slowly: Bayesian learning about political facts. The Journal of Politics, 79(4), 1403-1418. https://doi.org/10.1086/692739

Holtz, R., \& Norman, M. (1985). Assumed similarity and opinion certainty. Journal of Personality and Social Psychology, 48(4), 890-989.

Jackson, N. (2018). The rise of poll aggregation and election forecasting. In L. R. Atkinson \& R. M. Alvarez (Eds.), The Oxford Handbook of Polling and Survey Methods, 2018. Oxford University Press.

Jerit, J., \& Barabas, J. (2012). Partisan perceptual bias and the information environment. The Journal of Politics, 74(3), 672-684. https://doi.org/10.1017/S0022381612000187

Judd, C. M., Westfall, J., \& Kenny, D. A. (2012). Treating stimuli as a random factor in social psychology: A new and comprehensive solution to a pervasive but largely ignored problem. Journal of Personality and Social Psychology, 103(1), 54-69. https://doi.org/10.1037/a0028347

Judd, C. M., Westfall, J., \& Kenny, D. A. (2017). Experiments with more than one random factor: Designs, analytic models, and statistical power. Annual Review of Psychology, 68(1), 601-625. https://doi.org/10.1146/annurev-psych-122414-033702

Kim, S. T., Weaver, D., \& Willnat, L. (2000). Media reporting and perceived credibility of online polls. Journalism \& Mass Communication Quarterly, 77(4), 846-864. https://doi.org/10.1177/107769900007700408

Kunda, Z. (1990). The case for motivated reasoning. Psychological Bulletin, 108(3), 480-498.

Kuru, O., Pasek, J., \& Traugott, M. W. (2017). Motivated reasoning in the perceived credibility of public opinion polls. Public Opinion Quarterly, 81(2), 422-446. 


\section{TRUST IN POLLS}

https://doi.org/10.1093/poq/nfx018

Madson, G. J., \& Hillygus, D. S. (2019). All the best polls agree with me: Bias in evaluations of political polling. Political Behavior. https://doi.org/10.1007/s11109-019-09532-1

Mercer, A., Deane, C., \& McGreeney, K. (2016, November 9). Why 2016 election polls missed their mark. Pew Research.

https://www.pewresearch.org/fact-tank/2016/11/09/why-2016-election-polls-missed-their -mark/

Middleton, L. (2018). Demographic factors and trust in different news sources. Proceedings of the Association for Information Science and Technology, 55(1), 524-533.

Mourão, R. R., Thorson, E., Chen, W., \& Tham, S. M. (2018). Media repertoires and news trust during the early Trump administration. Journalism Studies, 19(13), 1945-1956. https://doi.org/10.1080/1461670X.2018.1500492

Nakagawa, S., Johnson, P. C. D., \& Schielzeth, H. (2017). The coefficient of determination R2 and intra-class correlation coefficient from generalized linear mixed-effects models revisited and expanded. Journal of the Royal Society Interface, 14(134).

Palan, S., \& Schitter, C. (2018). Prolific.ac_-A subject pool for online experiments. Journal of Behavioral and Experimental Finance, 17, 22-27. https://doi.org/10.1016/j.jbef.2017.12.004

Price, V., \& Stroud, N. J. (2005). Public attitudes toward polls: Evidence from the 2000 U.S. presidential election. International Journal of Public Opinion Research, 18(4), 393-421. https://doi.org/10.1093/ijpor/edh119

Prosser, C., \& Mellon, J. (2018). The twilight of the polls? A Review of trends in polling accuracy and the causes of polling misses. Government and Opposition, 53(4), 757-790. 


\section{TRUST IN POLLS}

https://doi.org/10.1017/gov.2018.7

Salwen, M. (1987). Credibility of newspaper opinion polls: Source, source intent and precision. Journalism Quarterly, 64(4), 813-819.

Searles, K., Smith, G., \& Sui, M. (2018). Partisan media, electoral predictions, and wishful thinking. Public Opinion Quarterly, 82(S1), 888-910. https://doi.org/10.1093/poq/nfy006

Sheffield, M. (2018, December 27). Survey: A majority of Americans don't believe polls are accurate. The Hill.

https://thehill.com/hilltv/what-americas-thinking/423023-a-majority-of-americans-are-sk eptical-that-public-opinion-polls

Tsfati, Y. (2001). Why do people trust media pre-election polls? Evidence from the Israeli 1996 elections. International Journal of Public Opinion Research, 13(4), 433-441. https://doi.org/10.1093/ijpor/13.4.433

Yglesias, M. (2020, November 1). The "shy Trump voters" debate, explained. Vox. https://www.vox.com/2020/11/1/21544644/shy-trump-voters-polling-error-explained 
TRUST IN POLLS

\section{Supplemental Materials}

\section{Study 1 Pilot Test}

We first conducted a pilot to examine the internal reliability of four two-item measures we developed for Study 1.

Participants: We recruited a convenience sample of 55 American participants on September 29th, 2020 on the Prolific survey platform (Palan \& Schitter, 2018), who participated in a 1 minute survey for $\$ 0.25$. The goal was to gather at least 50 usable responses for which to calculate Cronbach's alphas for each measure. Four participants failed our attention check, leaving a final $N_{\text {pilot }}=51$ (21 Male, $M_{\text {Age }}=30.41, \mathrm{SD}_{\text {Age }}=10.27$, Democrat/GOP/Independent=32/4/15). Participants viewed a single poll, with an accompanying description, showing Wisconsin voter preferences for Donald Trump vs. Joe Biden (stimuli here: https://osf.io/3dk52).

Procedure \& Result: Participants responded to eight survey items (order randomized, four reverse coded) along 1-7 Likert scales labeled "Strongly Disagree" to "Strongly Agree." These items captured the four judgments of interest: trust in the poll ("This poll's findings are credible/inaccurate(-)", $\mathrm{M}=4.66, \mathrm{SD}=1.31, \alpha=0.81)$, the perception that pollsters are unbiased ("These pollsters are trustworthy/biased(-)", M=4.47, $\mathrm{SD}=1.31 \alpha=0.76$ ), the perception that poll respondents are honest ("The people who responded to this poll [reported their true feelings/were dishonest(-)]", $\mathrm{M}=5.34, \mathrm{SD}=1.09, \alpha=0.87$ ), and agreement with the poll's results ("I share the opinion of the poll's majority" and "I hold the view expressed by the minority in the poll(-)", $\mathrm{M}=5.76, \mathrm{SD}=1.54, \alpha=0.94)$. Participants then responded to an attention check where they were asked "Please, in the box below, write out the answer to the following math problem, capitalizing the first letter of your answer (e.g. "Eight", not "eight" or "8"). What does one plus three equal?" 


\section{TRUST IN POLLS}

Any participants who did not answer "Four" were excluded from all analyses. Lastly, participants provided their age, gender identity, party affiliation (Democrat, Republican, Independent/Other), and responded to two items measuring economic/social political ideology on 1-7 Likert scales (“On [economic/social] issues, how do you identify politically?”, Labeled "Very Liberal" to "Very Conservative," $\mathrm{M}_{\text {econ }}=2.98, \mathrm{SD}_{\text {econ }}=1.62, \mathrm{M}_{\text {social }}=2.55, \mathrm{SD}_{\text {social }}=1.51$ ).

As we found reasonable internal reliabilities for our four two-item measurements, we proceeded with conducting our stimuli pretest, then study 1 . Study 1 used all the measures included in the pilot.

\section{Study 1 Stimuli Pretest}

We conducted a pretest of 60 poll stimuli, with the goal of obtaining a final stimuli set of polls for Study 1 which would be (i) on average neutral along the dimension of liberal-conservative favorability, but also (ii) widely distributed across that dimension such that the stimuli were broadly representative of polls as a whole (both political and non-political). We also wanted the presentation of the polls to be naturalistic, so presented participants with a screen-shot image of a poll's results directly from the reporting source of the poll (i.e., an online news article). Each image was accompanied by a short description which detailed the poll's topic and identified the pollsters who conducted the poll, but did not discuss the poll's results. We selected polls which touched on current political issues (e.g., presidential approval), and polls outside the domain of politics related to social preferences (e.g., the prevalence of supernatural beliefs).

Participants: Data collection was preregistered (https://osf.io/sn3x2). We recruited a convenience sample of 255 Americans split evenly across Democrats, Republicans, and Independents, on October 23rd, 2020 on the Prolific survey platform (Palan \& Schitter, 2018), 


\section{TRUST IN POLLS}

who participated in a 5 minute survey for $\$ 1.15 .17$ participants failed our attention check, leaving a final $N_{\text {pretest }}=239$ (133 Male/4 non-binary, $M_{\text {Age }}=32.07, \mathrm{SD}_{\text {Age }}=12.18$, Democrat/GOP/Independent=98/75/66).

Procedure \& Results: Participants were randomly assigned to view 15 of the 60 polls, guaranteeing that each poll would be judged by at least 60 participants. For each poll participants were asked a single 5-scale Likert item: "How favorable are these results to liberals or conservatives?" ("Strongly Favors Liberals", "Slightly Favors Liberal”, "Neutral in Favorability”, “Slightly Favors Conservatives”, “Strongly Favors Conservatives). Responses were coded -2 to +2 . Lastly, participants completed the attention check used in the pilot study, responded to basic demographic questions, and the survey ended. In aggregate the 60 polls were neutral in ideological favorability $(\mathrm{M}=0.02, \mathrm{SD}=1.11$ ), with 15 polls rated as $>0.5$ (favoring conservatives), $15<-0.5$ (favoring liberals) and 30 between -0.5 and 0.5 (neutral). We also found that partisans gave practically identical responses on average $($ Dems $=-0.01$, Repubs $=0.04$, Indep=0.04). Despite the achieved neutrality and breadth of poll favorability, we decided to remove four polls from the stimuli set (Poll \#5, 7, 13, and 39) either because participants expressed confusion over what the "majority" supported in the poll, or because there was low agreement in favorability. We also cropped the images of Polls \#26, 27, and 41 such that they pertained to a single poll question, not multiple. Removal of these four polls preserved the overall neutrality of the stimuli set $(\mathrm{M}=0.02, \mathrm{SD}=1.12)$, and the four removed were between -0.5 and 0.5 , preserving the equal distribution of liberal and conservative favoring polls. All 56 remaining polls were used as stimuli in Study 1.

\section{Cited:}




\section{TRUST IN POLLS}

Palan, S., \& Schitter, C. (2018). Prolific.ac-A subject pool for online experiments. Journal of Behavioral and Experimental Finance, 17, 22-27.

https://doi.org/10.1016/j.jbef.2017.12.004

\section{Study 3 Regression Models}

The primary results reported for Study 3 came from three linear-mixed effects models, all with differing dependent variables but the same set of predictors. Each model was either predicting trust in the poll, perceived respondent honesty, or perceptions of unbiased pollsters. Each dependent variable was predicted by a three-way interaction between Condition (Accurate, Overestimation, Underestimation), the party of the winning candidate in the poll (Democrat, Republican), and the party identification of the participant (Democrats/Dem-leaning Independents, Republicans/Rep-leaning Independents, True Independents). This allowed for the examination of main effects for condition, winner party, and participant party, but also the computing of group-contingent marginal means to test many of the predicted effects via pairwise comparison. The need to compute accurate marginal means (i.e., marginal means that don't assume congruence across groups) is why the three-way interactions were modeled, despite never being statistically significant. Supplemental Table 1 below displays the regression output for the three linear-mixture models.

\section{Table S1}

\begin{tabular}{|c|c|c|c|c|c|c|c|c|c|}
\hline \multirow[b]{2}{*}{ Predictors } & \multicolumn{3}{|c|}{ Trust } & \multicolumn{3}{|c|}{ Unbiased Pollsters } & \multicolumn{3}{|c|}{ Honest Respondents } \\
\hline & $\begin{array}{l}\text { Std } \\
\text { Beta }\end{array}$ & $95 \% C I$ & $p$ & $\begin{array}{l}\text { Std } \\
\text { Beta }\end{array}$ & $95 \% C I$ & $p$ & $\begin{array}{l}\text { Std. } \\
\text { Beta }\end{array}$ & $95 \% C I$ & $p$ \\
\hline (Intercept) & -0.04 & $\begin{array}{c}-0.22- \\
0.14\end{array}$ & 0.649 & -0.03 & $\begin{array}{c}-0.17- \\
0.12\end{array}$ & 0.689 & -0.02 & $\begin{array}{c}-0.16- \\
0.11\end{array}$ & 0.721 \\
\hline $\begin{array}{l}\text { Condition } \\
\text { [Accurate] }\end{array}$ & 0.55 & $\begin{array}{c}0.31- \\
0.79\end{array}$ & $<0.001$ & 0.44 & $\begin{array}{c}0.26- \\
0.62\end{array}$ & $<0.001$ & 0.40 & $\begin{array}{c}0.23- \\
0.56\end{array}$ & $<0.001$ \\
\hline $\begin{array}{l}\text { Condition } \\
\text { [Overestimated] }\end{array}$ & -0.21 & $\begin{array}{c}-0.45- \\
0.03\end{array}$ & 0.082 & -0.18 & $\begin{array}{c}-0.36- \\
0.00\end{array}$ & 0.055 & -0.17 & $\begin{array}{c}-0.34- \\
-0.01\end{array}$ & 0.042 \\
\hline
\end{tabular}


TRUST IN POLLS

\begin{tabular}{|c|c|c|c|c|c|c|c|c|c|}
\hline Winner [Democrat] & -0.02 & $\begin{array}{c}-0.19- \\
0.15\end{array}$ & 0.800 & -0.01 & $\begin{array}{c}-0.14- \\
0.11\end{array}$ & 0.818 & 0.01 & $\begin{array}{c}-0.10- \\
0.13\end{array}$ & 0.806 \\
\hline $\begin{array}{l}\text { Party ID } \\
\text { [Democrat] }\end{array}$ & 0.09 & $\begin{array}{c}0.01- \\
0.17\end{array}$ & 0.026 & 0.10 & $\begin{array}{c}0.01- \\
0.19\end{array}$ & 0.037 & 0.08 & $\begin{array}{c}-0.01- \\
0.18\end{array}$ & 0.080 \\
\hline $\begin{array}{l}\text { Party ID [True } \\
\text { Indep] }\end{array}$ & -0.10 & $\begin{array}{c}-0.22- \\
0.02\end{array}$ & 0.119 & -0.06 & $\begin{array}{c}-0.20- \\
0.08\end{array}$ & 0.400 & -0.05 & $\begin{array}{c}-0.19- \\
0.09\end{array}$ & 0.496 \\
\hline $\begin{array}{l}\text { Cond. [Accurate] x } \\
\text { Winner [Dem] }\end{array}$ & 0.04 & $\begin{array}{c}-0.20- \\
0.28\end{array}$ & 0.743 & -0.01 & $\begin{array}{c}-0.19- \\
0.17\end{array}$ & 0.904 & 0.00 & $\begin{array}{c}-0.16- \\
0.17\end{array}$ & 0.976 \\
\hline $\begin{array}{l}\text { Cond. [Over] x } \\
\text { Winner [Dem] }\end{array}$ & -0.06 & $\begin{array}{c}-0.30- \\
0.19\end{array}$ & 0.624 & -0.03 & $\begin{array}{c}-0.22- \\
0.15\end{array}$ & 0.693 & -0.02 & $\begin{array}{c}-0.19- \\
0.15\end{array}$ & 0.793 \\
\hline $\begin{array}{l}\text { Cond. [Accurate] x } \\
\text { Party [Dem] }\end{array}$ & -0.03 & $\begin{array}{c}-0.08- \\
0.03\end{array}$ & 0.334 & -0.01 & $\begin{array}{c}-0.06- \\
0.05\end{array}$ & 0.757 & 0.02 & $\begin{array}{c}-0.04- \\
0.07\end{array}$ & 0.578 \\
\hline $\begin{array}{l}\text { Cond. [Over] x } \\
\text { Party [Dem] }\end{array}$ & 0.05 & $\begin{array}{c}-0.01- \\
0.10\end{array}$ & 0.110 & 0.03 & $\begin{array}{c}-0.03- \\
0.08\end{array}$ & 0.352 & 0.02 & $\begin{array}{c}-0.04- \\
0.08\end{array}$ & 0.480 \\
\hline $\begin{array}{l}\text { Cond. [Accurate] x } \\
\text { Winner [Indep] }\end{array}$ & 0.09 & $\begin{array}{c}0.00- \\
0.17\end{array}$ & 0.047 & 0.08 & $\begin{array}{c}-0.00- \\
0.16\end{array}$ & 0.064 & 0.05 & $\begin{array}{c}-0.03- \\
0.13\end{array}$ & 0.247 \\
\hline $\begin{array}{l}\text { Cond. [Over] x } \\
\text { Winner [Indep] }\end{array}$ & -0.06 & $\begin{array}{c}-0.15- \\
0.02\end{array}$ & 0.161 & -0.07 & $\begin{array}{c}-0.15- \\
0.02\end{array}$ & 0.124 & -0.05 & $\begin{array}{c}-0.13- \\
0.03\end{array}$ & 0.234 \\
\hline $\begin{array}{l}\text { Winner [Dem] x } \\
\text { Party [Dem] }\end{array}$ & 0.05 & $\begin{array}{c}0.01- \\
0.09\end{array}$ & 0.023 & 0.04 & $\begin{array}{c}0.00- \\
0.08\end{array}$ & 0.037 & 0.03 & $\begin{array}{c}-0.01- \\
0.06\end{array}$ & 0.194 \\
\hline $\begin{array}{l}\text { Winner [Dem] x } \\
\text { Party [Indep] }\end{array}$ & -0.03 & $\begin{array}{c}-0.09- \\
0.03\end{array}$ & 0.366 & -0.00 & $\begin{array}{c}-0.06- \\
0.06\end{array}$ & 0.922 & 0.02 & $\begin{array}{c}-0.04- \\
0.08\end{array}$ & 0.445 \\
\hline $\begin{array}{l}\text { Cond. [Acc.] x } \\
\text { Winner [Dem] x } \\
\text { Party [Dem] }\end{array}$ & -0.05 & $\begin{array}{c}-0.10- \\
0.01\end{array}$ & 0.116 & 0.02 & $\begin{array}{c}-0.03- \\
0.08\end{array}$ & 0.378 & 0.03 & $\begin{array}{c}-0.03- \\
0.08\end{array}$ & 0.367 \\
\hline $\begin{array}{l}\text { Cond. [Over] x } \\
\text { Winner [Dem] x } \\
\text { Party [Dem] }\end{array}$ & -0.00 & $\begin{array}{c}-0.06- \\
0.05\end{array}$ & 0.925 & -0.01 & $\begin{array}{c}-0.06- \\
0.05\end{array}$ & 0.823 & -0.05 & $\begin{array}{c}-0.11- \\
0.00\end{array}$ & 0.070 \\
\hline $\begin{array}{l}\text { Cond. [Acc.] x } \\
\text { Winner [Dem] x } \\
\text { Party [Indep] }\end{array}$ & 0.06 & $\begin{array}{c}-0.02- \\
0.15\end{array}$ & 0.154 & -0.03 & $\begin{array}{c}-0.11- \\
0.05\end{array}$ & 0.484 & -0.02 & $\begin{array}{c}-0.10- \\
0.06\end{array}$ & 0.663 \\
\hline $\begin{array}{l}\text { Cond. [Over] x } \\
\text { Winner [Dem] x } \\
\text { Party [Indep] }\end{array}$ & -0.03 & $\begin{array}{c}-0.12- \\
0.05\end{array}$ & 0.441 & 0.03 & $\begin{array}{c}-0.06- \\
0.11\end{array}$ & 0.507 & 0.03 & $\begin{array}{c}-0.06- \\
0.11\end{array}$ & 0.521 \\
\hline \multicolumn{10}{|l|}{ Random Effects } \\
\hline$\sigma^{2}$ & 0.52 & & & 0.50 & & & 0.49 & & \\
\hline \multirow[t]{2}{*}{$\tau_{00}$} & 0.26 ID & & & $0.37 \mathrm{ID}$ & & & $0.40_{\mathrm{ID}}$ & & \\
\hline & $0.11_{\text {Poll }}$ & & & 0.06 Poll & & & 0.05 Poll & & \\
\hline $\mathrm{ICC}$ & 0.41 & & & 0.46 & & & 0.47 & & \\
\hline \multirow[t]{2}{*}{$\mathrm{N}$} & $498_{\mathrm{ID}}$ & & & $498_{\mathrm{ID}}$ & & & $498_{\mathrm{ID}}$ & & \\
\hline & $18_{\text {Poll }}$ & & & $18_{\text {Poll }}$ & & & $18_{\text {Poll }}$ & & \\
\hline Observations & 2988 & & & 2988 & & & 2988 & & \\
\hline $\begin{array}{l}\text { Marginal } \mathrm{R}^{2} / \\
\text { Conditional } \mathrm{R}^{2}\end{array}$ & $0.142 / 0$ & & & $0.095 / \mathrm{C}$ & & & $0.080 / 0$ & & \\
\hline
\end{tabular}

Table S1: Mixed-effects regression models predicting trust in polls, perceptions of unbiased pollsters, and perceived respondent honesty. All models have crossed random effects for participant and poll, and all dependent variables are z-scored. All predictors are factor variables with sum coding. 
TRUST IN POLLS

\section{Study 3 Further Findings}

Win-Less Effect: We find no evidence for the "Win-Less" Effect. Among Republicans and Republican-leaning Independents reacting to Republican wins, there was no difference in trust toward polls which overestimated the win margin $(M=4.38, S D=1.57)$ relative to polls which underestimated the win margin $(M=4.21, S D=1.51, p=0.671, \beta=0.12)$, nor in perceived pollster bias of overestimating $(M=4.50, S D=1.39)$ relative to underestimating polls $(M=4.22, S D=1.31, p=0.327, \beta=0.21)$ or perceived respondent honesty in overestimating $(M$ $=4.72, S D=1.31)$ relative to underestimating polls $(M=4.66, S D=1.32, p=0.825, \beta=0.04)$. The same pattern emerged for Democratic and Democratic-leaning participants reacting to Democratic wins. There was no difference in Democrats' trust toward polls which overestimated the win margin $(M=4.45, S D=1.39)$ relative to polls which underestimated the win maring $(M$ $=4.36, S D=1.53, p=0.805, \beta=0.07)$, nor in perceived pollster bias of overestimating $(M=$ $4.53, S D=1.34)$ relative to underestimating polls $(M=4.45, S D=1.40, p=0.757, \beta=0.07)$ or perceived respondent honesty in overestimating $(M=4.79, S D=1.24)$ relative to underestimating polls $(M=4.82, S D=1.30, p=0.953, \beta=-0.01)$.

Because a null Win-Less Effect supports our theorizing, we attempted to "find" a Win-Less Effect by engaging in non-conservative model specifications. All attempts yielded further null results. When we dropped the Accurate Poll Condition from the data to increase statistical power, collapsed across parties, and just examined the Overestimation-Underestimation Condition contrast for polls where the participant's in-party won, we still observed no significant difference for trust $(p=0.625, \beta=0.10)$, perceived pollster bias $(p=0.355, \beta=0.14)$, or perceived respondent honesty $(p=0.897, \beta=0.02)$. As such, we conclude that there is no evidence for the Win-Loss effect. 


\section{TRUST IN POLLS}

Lose-More Effect: We find no evidence for the "Lose-More" Effect. Among Republicans and Republican-leaning Independents reacting to Democratic wins, there was no difference in trust toward polls which overestimated the win margin $(M=4.17, S D=1.49)$ relative to polls which underestimated the win maring $(M=4.02, S D=1.55, p=0.770, \beta=$ $0.08)$, nor in perceived pollster bias of overestimating $(M=4.18, S D=1.32)$ relative to underestimating polls $(M=4.20, S D=1.27, p=0.919, \beta=-0.02)$ or perceived respondent honesty in overestimating $(M=4.62, S D=1.25)$ relative to underestimating polls $(M=4.54, S D$ $=1.29, p=0.811, \beta=0.05)$. The same pattern emerged for Democratic and Democratic-leaning participants reacting to Republican wins. There was no difference in Democrats' trust toward polls which overestimated the win margin $(M=4.53, S D=1.44)$ relative to polls which underestimated the win maring $(M=4.03, S D=1.35, p=0.264, \beta=0.32)$, nor in perceived pollster bias of overestimating $(M=4.55, S D=1.32)$ relative to underestimating polls $(M=4.27$, $S D=1.30, p=0.358, \beta=0.20)$ or perceived respondent honesty in overestimating $(M=4.86, S D$ $=1.26)$ relative to underestimating polls $(M=4.57, S D=1.32, p=0.268, \beta=0.22)$.

Because a null Lose-More Effect supports our theorizing, we attempted to "find" a Lose-More Effect by engaging in non-conservative model specifications. All attempts yielded further null results. When we dropped the Accurate Poll Condition from the data to increase statistical power, collapsed across parties, and just examined the Overestimation-Underestimation Condition contrast for polls where the participant's out-party won, we still observed no significant difference for trust $(p=0.319, \beta=0.21)$, perceived pollster bias $(p=0.554, \beta=0.09)$, or perceived respondent honesty $(p=0.316, \beta=0.14)$. As such, we conclude that there is no evidence for the Lose-More effect. 


\section{TRUST IN POLLS}

Partisanship and Ideology: Relative to Republicans, Democrats expressed greater trust $(p=0.026, \beta=0.09)$ and less perceived pollster bias $(p=0.037, \beta=0.10)$, but no greater respondent honesty $(p=0.806, \beta=0.01)$. Self-reported economic conservative (bi-polar measure) was negatively associated with trust $(p=0.017, \beta=-0.06)$, the perception of unbiased pollsters $(p=0.004, \beta=-0.09)$, and perceived respondent honesty $(p=0.018, \beta=-0.07)$. Similarly, self-reported social conservative (bi-polar measure) was negatively associated with trust $(p=0.020, \beta=-0.06)$, the perception of unbiased pollsters $(p<0.001, \beta=-0.12)$, and perceived respondent honesty $(p=0.003, \beta=-0.09)$. However, as these associations never interacted with Condition, they were consistent across polls which predicted negative and positive outcomes for Republican candidates. 